\title{
Oxidative and anti-oxidative effect of anesthesia compounds (ketamine and xylazine) on the rabbit blood sample using electrochemical method
}

\author{
Dunya Ali Mustafa', Bahaa Hadi Mohammed², Muhammed Mizher Radhi' \\ ${ }^{1}$ Radiological Techniques Department, Health and Medical Technology College-Baghdad, \\ Middle Technical University (MTU), Iraq \\ ${ }^{2}$ Anesthesia Techniques Department, Health and Medical Technology College-Baghdad, \\ Middle Technical University (MTU), Iraq
}

\begin{abstract}
Ketamine $(\mathrm{KN})$ and xylazine $(\mathrm{XZ})$ are one of the famous anesthesias using for the animal. The electrochemical properties of the $\mathrm{KN}$ and $\mathrm{XZ}$ compounds in the rbbit blood samples were studied by cyclic voltammetric (CV) technique using glassy carbon electrode (GCE). The study was included different concentrations, $\mathrm{pH}$, scan rates, interferences between them ( $\mathrm{KN}$ and $\mathrm{XZ}$ ) and reliability (stability). The oxidation-reduction current peaks was studied of the $\mathrm{KN}$ and $\mathrm{XZ}$ alone and both (mixed) in the blood medium to determine the effect of these compounds on the blood components.

It was found the oxidation- reduction current peaks for mixed of $\mathrm{KN}$ and $\mathrm{XZ}$ in blood medium at 0.1 and $-0.8 \mathrm{~V}$ respectively, and the oxidation peak was enhanced in acidic $\mathrm{pH}(3)$, while the reduction peaks was enhanced in alkaline $\mathrm{pH}$ (8). Also, the mixing of $\mathrm{KN}$ and $\mathrm{XZ}$ in blood medium was acted to decrease the oxidation peak and enhance the reduction peak, so it can be said that mixing is best to work in the animal state.
\end{abstract}

Keywords: cyclic voltammetry, ketamine, xylazine, rabbit, blood, redox process

\section{INTRODUCTION}

Initial studies using electrochemical analysis to finding the oxidation - reduction properties have been made for different pharmaceutical materials and their effects on the blood composition [1-5].

Xylazine may be inhaled or the drug will be used as a veterinary anesthetic. The recommended dose varies between species given intravenously, intramuscularly, subcutaneously or orally, either by itself or in combination with other anesthetics, such as ketamine which is a drug primarily used to initiate and maintain anesthesia [6,7]. The chemical structure of xylazine and ketamine illustrated in Figure 1 and 2 respectively.<smiles>Cc1cccc(C)c1NC1=NCCCS1</smiles>

FIGURE 1. Structure of xylazine<smiles>CN[C@@]1(c2ccccc2Cl)CCCCC1=O</smiles>

FIGURE 2. Structure of ketamine 
The electrochemical behavior of ketamine is studied through the use of cyclic voltammetry $(\mathrm{CV})$ in global buffers with a $\mathrm{pH}$ ranging from 2.0-12.0. Kinetic parameters, such as transport coefficients, propagation coefficients, and heterogeneous constant values of the forward rate were evaluated using these techniques. The CV was used to estimate ketamine in selected drug combinations [8].

Analytical electrical sensor ketamine was first reported using [bpy 3] 2+ as an electrochemical sensor probe. The niche of this electrolysis method is the absence of any sample before treatment, as well as being cost-effective and time-consuming. The methodology showed that it is useful for measuring low levels, $\mathrm{ng} / \mathrm{ml}$, and ketamine not only in buffered solutions but also in alcoholic beverages [9].

Ketamine is one of the most widely abused drugs in the world and poses a serious threat to human health and social stability; therefore, the ability to monitor the substance accurately in real time is essential. However, there are still many problems facing this goal, such as the generally low concentration of disturbed target molecules in complex samples that are subject to analysis during criminal investigations. In this work, careful and selective detection of ketamine by a molecularly printed electrochemical sensor [10].

The first time, an electrochemical study of xylazine in water and organic media suggested a quantitative method using a glass carbon electrode. A simple and accurate quantitative method was performed using a pulse differential voltage measurement. Under improved experimental conditions, a linear analytic curve was obtained for xylase concentrations ranging from 0.5 to $256 \mathrm{~L}$ with, with a maximum detection of $120 \mathrm{nmol} / 1$. The proposed method for determining xylazine was applied in pharmaceutical preparations [11].

Electrochemical techniques were used to estimate xylazine hydrochloric acid (XLZ) in bulk powder, drug manufacturing and human serum. Electrical oxidation of XLZ in multilayer carbon nanotubes (MWCNT), methyl fluorophosphates ion crystal 1-n-butylinidium (BMH) and sodium dodecyl sulfate (SDS) MWCNT-BMH-SDS) with $\mathrm{pH}=7.0$, studied in many of different dielectric structures and $\mathrm{pH}$ values. Effective experiments and parameters were improved to adhere to the evaluation of XLZ, and detection limit was observed as $4.80 \mathrm{~nm}$. The accuracy and accuracy of the method recognized was tested by retrieval studies with good frequency and reproducibility of the estimated method. The drop method was successfully practiced in the form of a dose and an oblique serum $[12,13]$.

In the current research, the effect of $\mathrm{KN}$ and $\mathrm{XZ}$ compounds on the rabbit blood samples by electrochemical analysis using cyclic voltammetric method to determine the redox current peaks of the Anesthesia Compounds (Ketamine and Xylazine).

\section{EXPERIMENTAL}

\section{Materials}

Anesthesia materials used to anesthetize animals such as ketamine $10 \%$ from Alfasan company (Holland), xylazine 2\% from Alfasan (Holland), blood samples received from rabbit type (Oryctolagus cuniculus), Normal saline $(0.9 \% \mathrm{NaCl}$ W/V) from Alcon Parenterals (India) Ltd, 0.1 M HCl and $0.1 \mathrm{M} \mathrm{NaOH}$ solutions.

\section{METHOD}

Cyclic voltammetry (CV) device contain a potential station type EZstat (Potentiostat / Glvanostat) from NuVant Systems Company (USA). The cell of CV made from quartz size of $15 \mathrm{ml}$ within the electrolyte solution (blood samples) is placed inside the blood of the working glass-carbon electrode (GCE), the reference electrode type silver/ silver chloride and an auxiliary electrode as platinum wire. All three electrodes immersed in the blood sample of the CV cell, and these three electrodes connected to the potentiostat and with personal computer to determine the voltammogram of the results as shown in Figure 3 [14].

\section{RESULTS AND DISCUSSION}

In this study, a cyclic voltammetric technique was used to determine the oxidative and reductive peaks of each of ketamine and xylazine compositions as well as both in rabbit blood samples. The study included different concentrations, scan rates, $\mathrm{pH}$, and reliability (stability). 


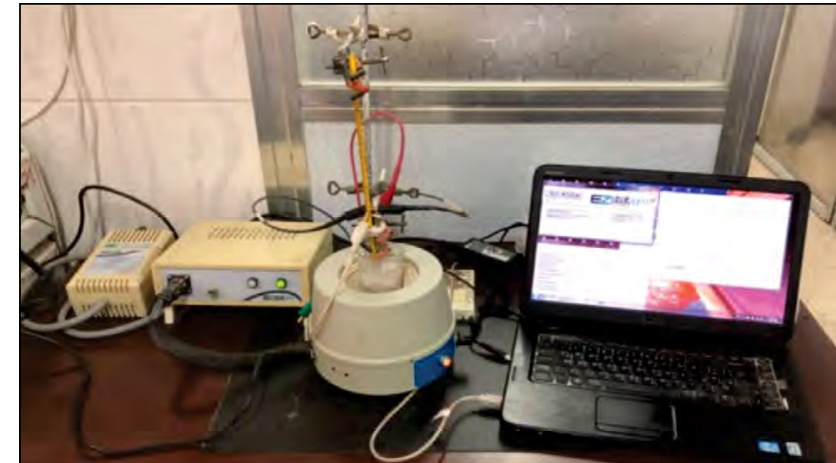

FIGURE 3. Cyclic voltammetry set up

\section{Calibration study}

From the results the effect of using different concentrations of both ketamine $(\mathrm{KN})$ and xylazine (XZ) as well as both of them was studied in the rabbit blood samples to identify the reaction of oxidation - reduction current peaks.

\section{Effect of the ketamine compound on the blood medium}

Figure 4 shows the cyclic voltammogram of ketamine $10 \%$ at different concentrations in rabbit blood medium which indicate the oxidation - reduction current peaks at potential of 1 and $-0.8 \mathrm{~V}$ respectively.

Through the relationship between the electrical current and the concentrations of ketamine in the rabbit blood sample, Figure 5 showed that the effect of the concentration of ketamine in the blood on the oxidation peak in the cyclic voltammogram which illustrated a leaner line by equation $\mathrm{y}=$ $39 x+25.68$, with good sensitivity $\mathrm{R}^{2}=0.8973$ [15]. The oxidation current peak of ketamine compound in the blood sample was increased, also the same behavior in the reduction peak has increased to the different concentrations of the ketamine according to the equation: $y=31.721 x+19.894$, with good sensitivity $\mathrm{R}^{2}=0.8864$ as shown in Figure 6 [16].

Effect the mix of ketamine and xylazine on the blood medium

New phenomena has been found for the effect of the mix of ketamine and xylazine on the blood components at different concentrations as shown in Figure 7 which illustrated the cyclic voltammogram of the oxidation current peak was decreased with the relationship in Figure 8 by equation: $y=$ $-769.09 x+32.42$ with good sensitivity of $\mathrm{R}^{2}=$ 0.8667 , while the reduction peak was enhanced with relationship of Figure 9 by euation of $\mathrm{y}=$ $120.3 x+20.767$ with good sensitivity $\mathrm{R}^{2}=0.8233$, so the mix of $\mathrm{KN}$ and $\mathrm{XZ}$ acts as anti-oxidative anesthesia in blood medium [17].

\section{Effect different scan rates}

Figure 10 illustrated the cyclic voltammogram of mix of $\mathrm{XZ}$ and $\mathrm{KN}$ in blood sample at different scan rates which enhanced the redox peaks against to increasing the scan rates. Figure 11 shows the current of oxidation-reduction peaks linearly in-

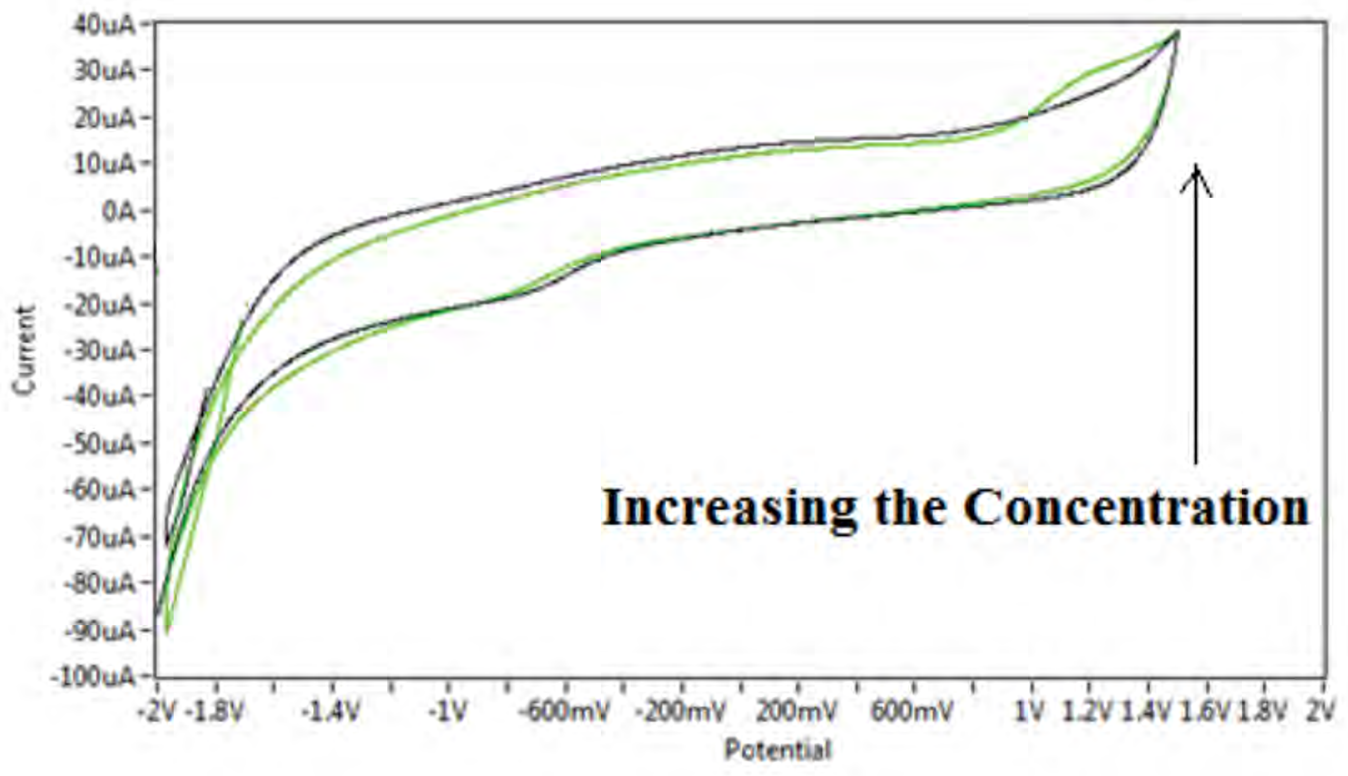

FIGURE 4. Cyclic voltammogram of different concentrations of ketamine $10 \%$ in blood medium using GCE versus $\mathrm{Ag} / \mathrm{AgCl}$ reference electrode at scan rate of $0.1 \mathrm{Vsec}-1$ 


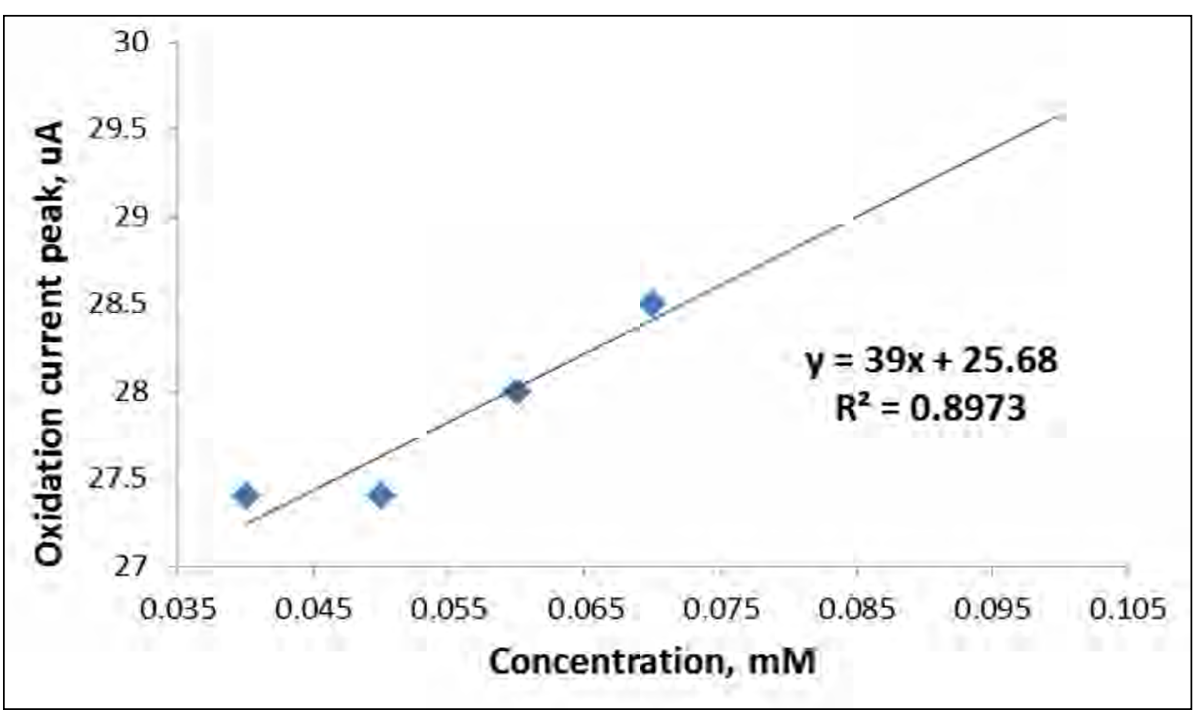

FIGURE 5. Relationship between oxidation current peak and different concentration ketamine $10 \%$ in rabbit blood sample

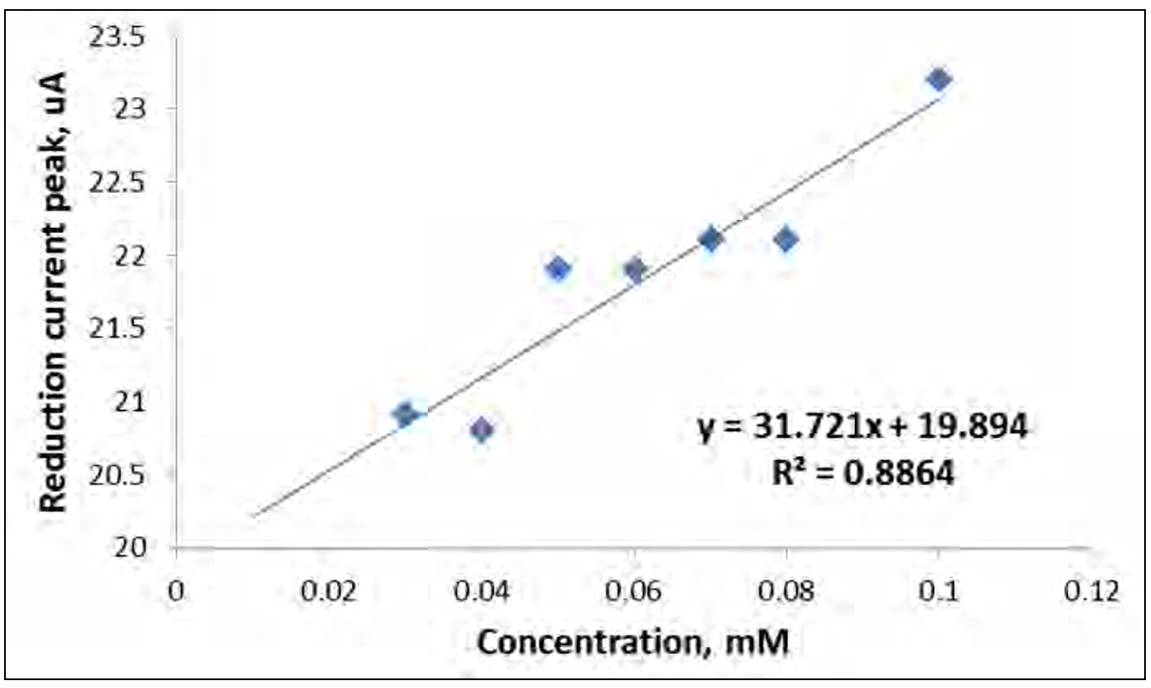

FIGURE 6. Relationship between reduction current peak and different concentration of ketamine $10 \%$ in rabbit blood sample

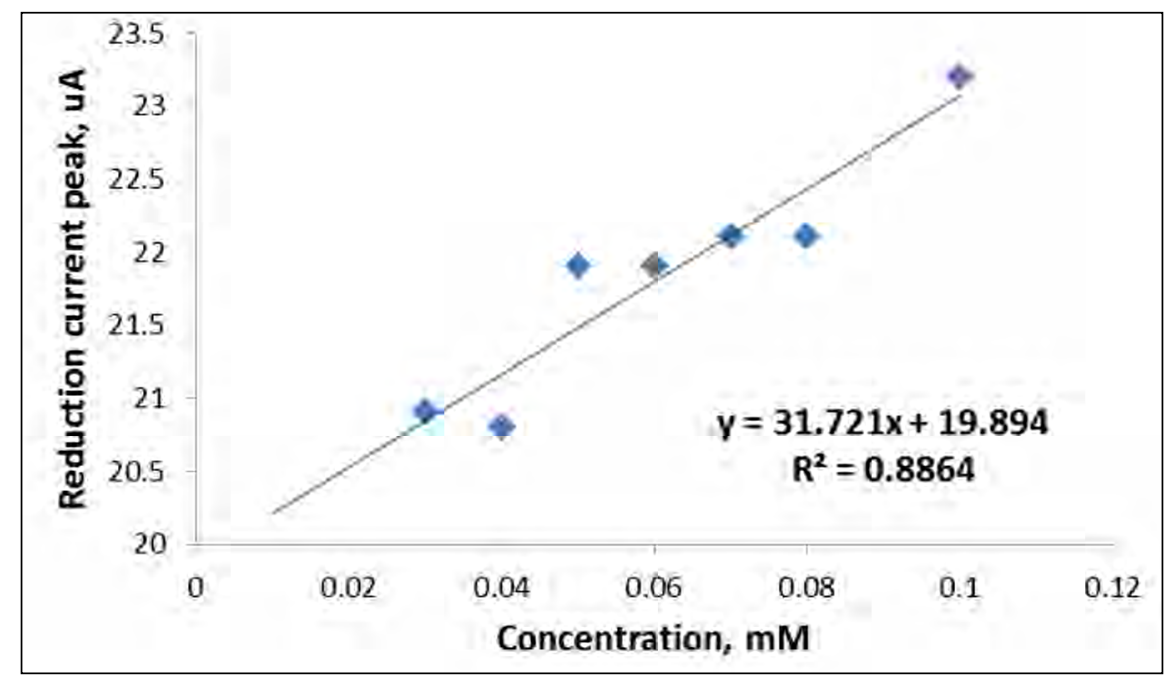

FIGURE 7. Cyclic voltammogram of different concentrations of Xylazine $2 \%$ in $0.1 \mathrm{mM}$ ketamine 10\% in blood medium using GCE versus $\mathrm{Ag} / \mathrm{AgCl}$ reference electrode at scan rate of $0.1 \mathrm{Vsec}-1$ 


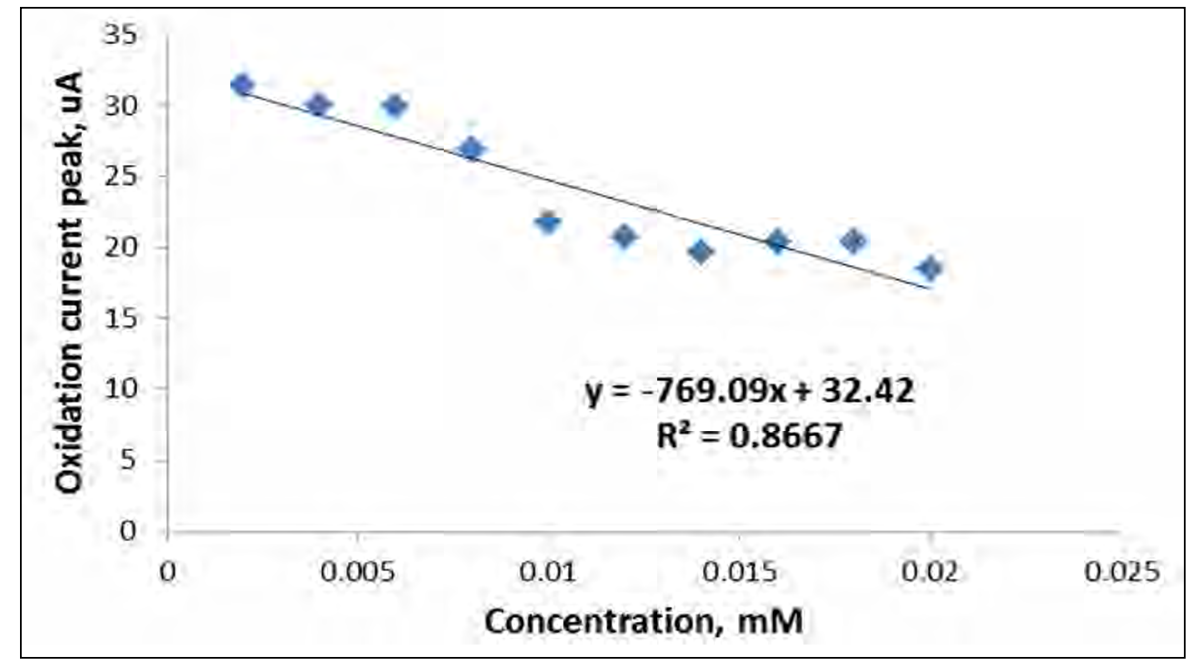

FIGURE 8. Relationship between oxidation current peak and different concentration of mix of ketamine $10 \%$ and xylazine $2 \%$ in rabbit blood sample

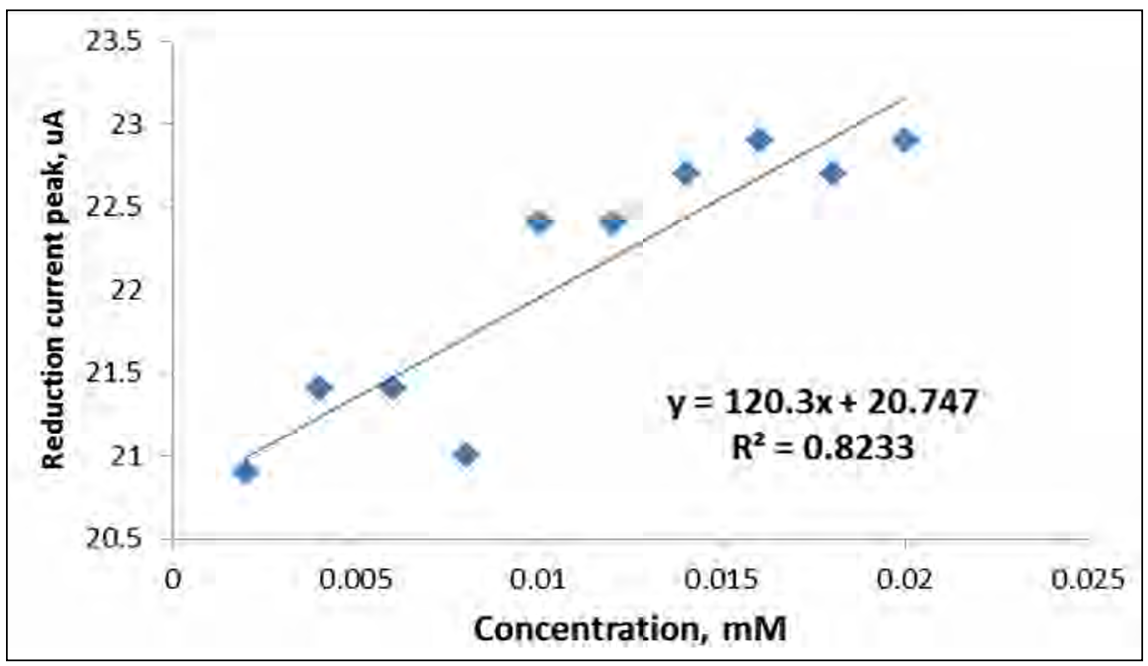

FIGURE 9. Relationship between reduction current peak and different concentration of mix of ketamine $10 \%$ and xylazine $2 \%$ in rabbit blood sample

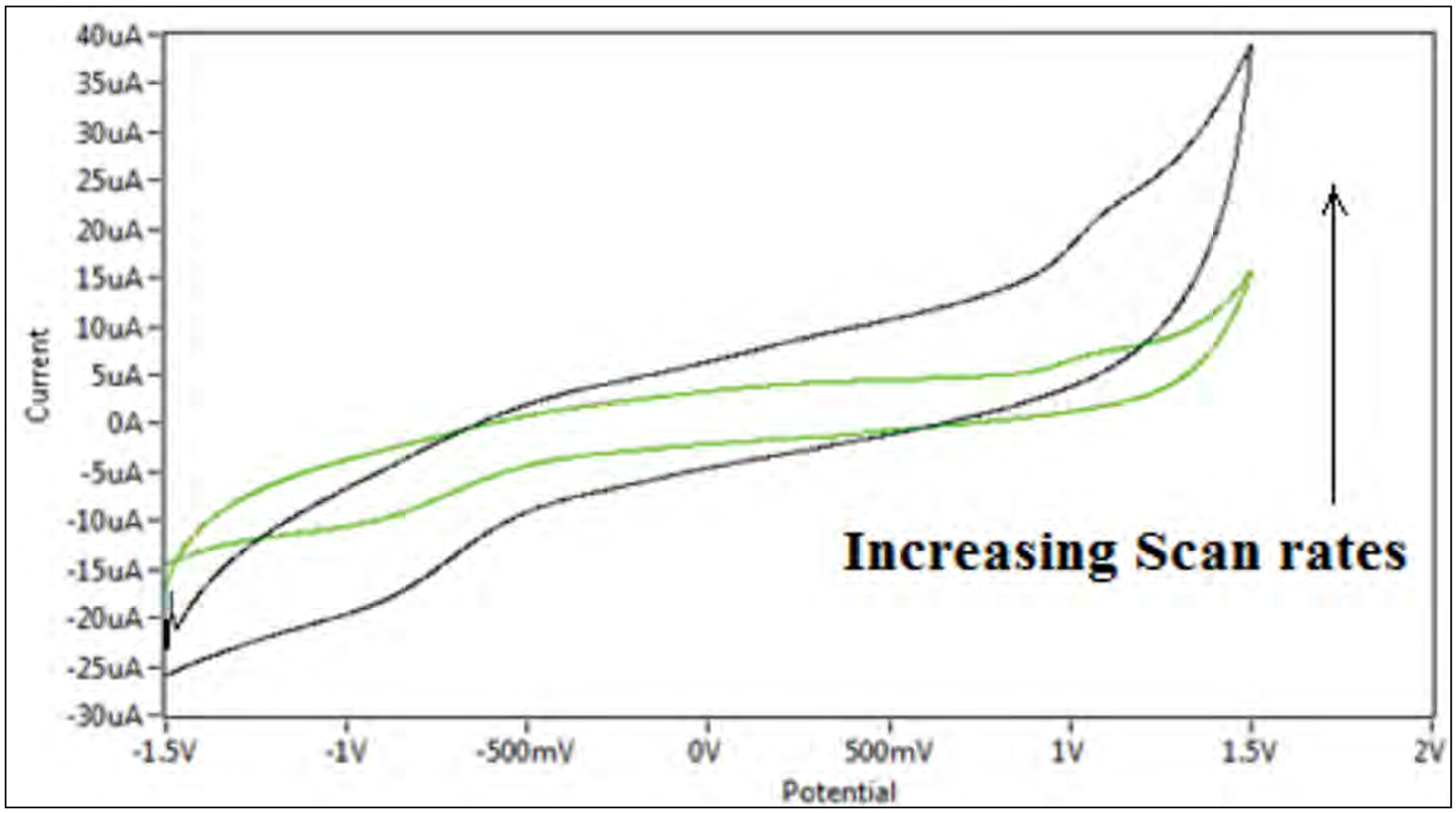

FIGURE 10. Cyclic voltammogram of Xylazine $2 \%$ and ketamine $10 \%$ in blood medium using GCE versus Ag/AgCl reference electrode at different scan rate of $0.01-0.1 \mathrm{Vsec}-1$ 


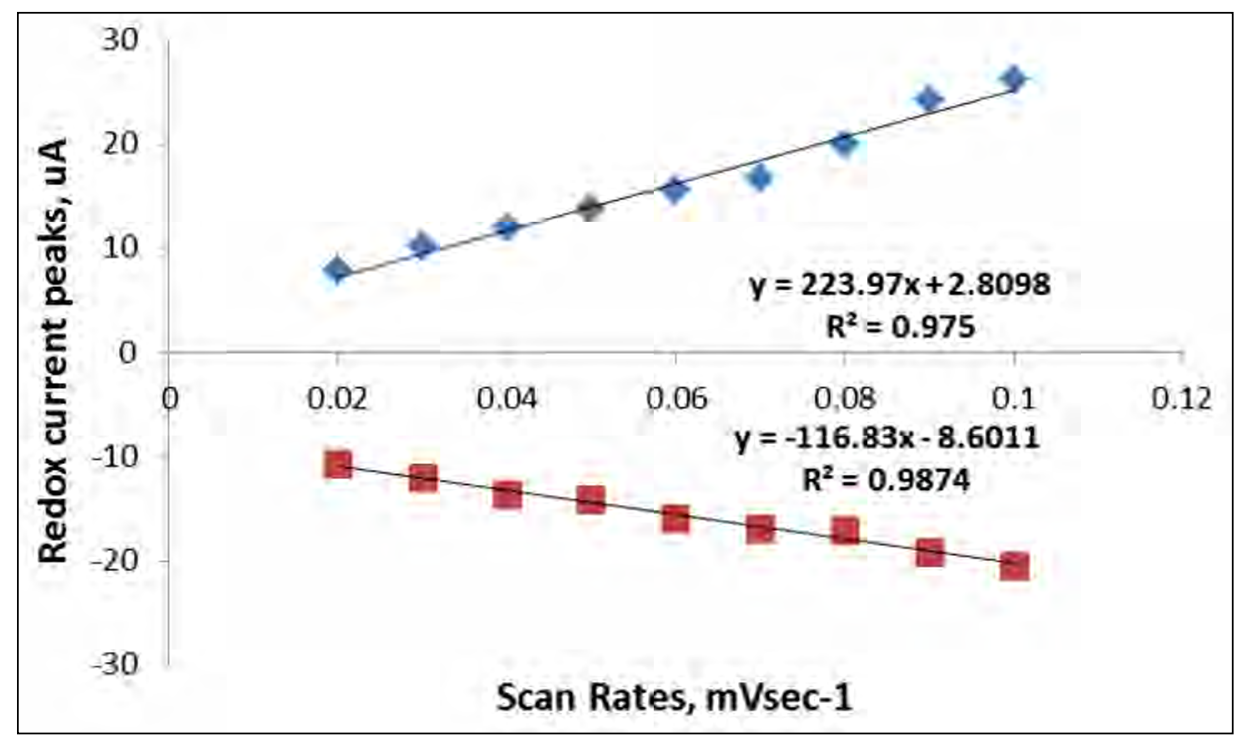

FIGURE 11. Relationship between redox current peaks and different scan rates (0.01-0.1 mVsec-1) of mix of Xylazine $2 \%$ and ketamine $10 \%$ in rabbit blood medium

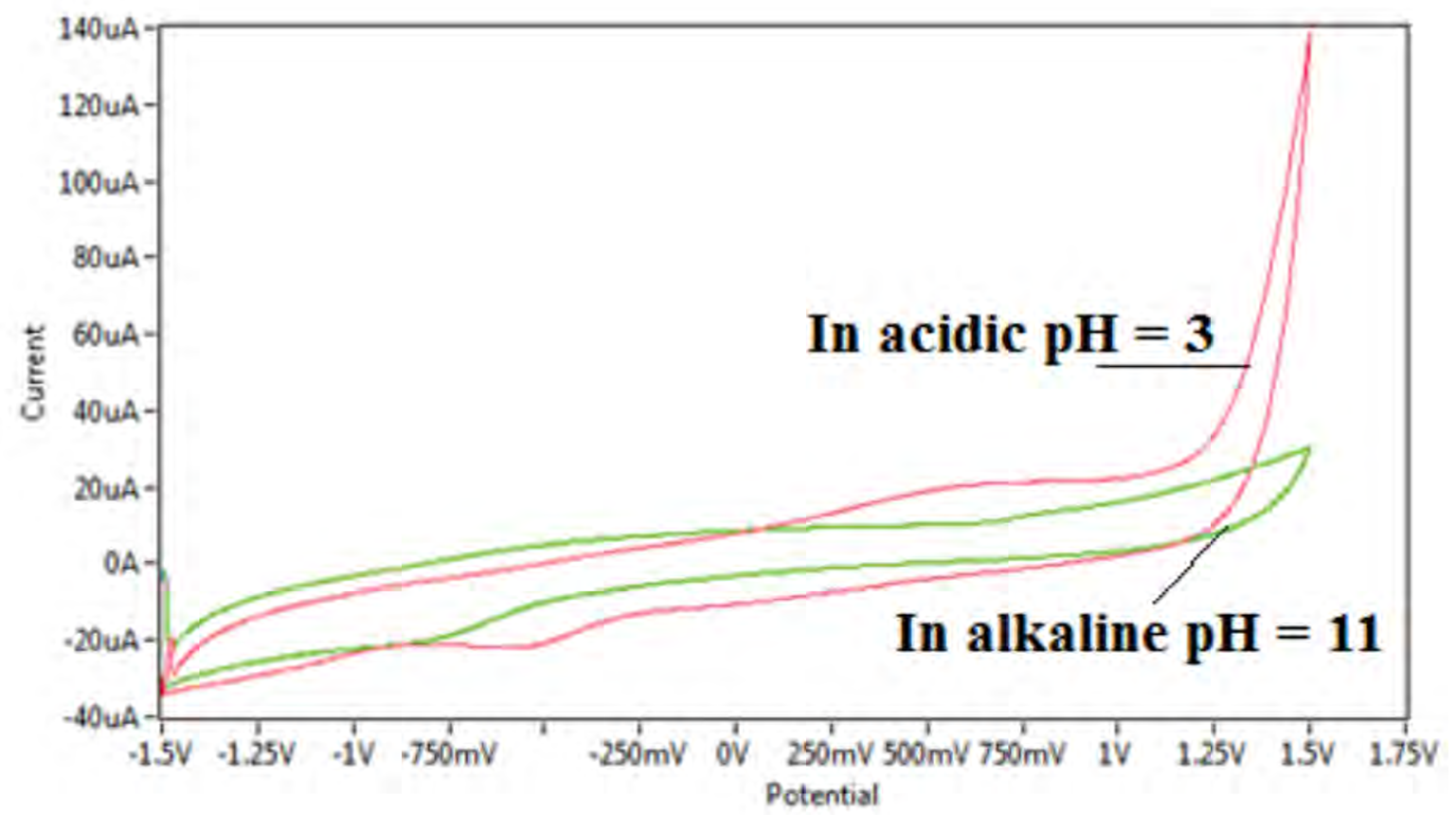

FIGURE 12. Cyclic voltammogram of Xylazine $2 \%$ and ketamine $10 \%$ in blood medium at different $\mathrm{pH}$ using $\mathrm{GCE}$ versus $\mathrm{Ag} / \mathrm{AgCl}$ reference electrode at scan rate $0.1 \mathrm{Vsec}-1$

creases Ipa $=223.97 \mathrm{SR}+2.8098$ with good sensitivity $\mathrm{R}^{2}=0.975$ and $\mathrm{Ipc}=-116.83 \mathrm{SR}-8.6011$ with good sensitivity of $\mathrm{R}^{2}=0.9874$, respectively. The electrochemical process of the mix of $\mathrm{XZ}$ and $\mathrm{KN}$ in blood medium on the GCE was suggested as adsorption controls [18].

Also, it can be determined the diffusion coefficient $\left(D_{f}\right)$ values of the oxidation - reduction reaction of mix $\mathrm{XZ}$ and $\mathrm{KN}$ compound in blood medi- um which depended on the components Randles-Seveik equation $[19,20]$ :

$$
\mathrm{I}_{\mathrm{p}}=\left(2.69 \times 10^{5}\right) \mathrm{n}^{3 / 2} \mathrm{AC} \mathrm{D}_{\mathrm{f}}^{1 / 2} \mathrm{~V}^{1 / 2}
$$

Where Ip the current peak, n, C and A indicate the number of electron moles that transferred in this reaction, charge transferred (Colomb) and the electrode area $\left(\mathrm{cm}^{2}\right)$, respectively. The $\mathrm{D}_{\mathrm{f}}$ and $\mathrm{V}$ indicate the diffusion coefficient $\left(\mathrm{cm}^{2} / \mathrm{s}\right)$ and potential, respectively. 


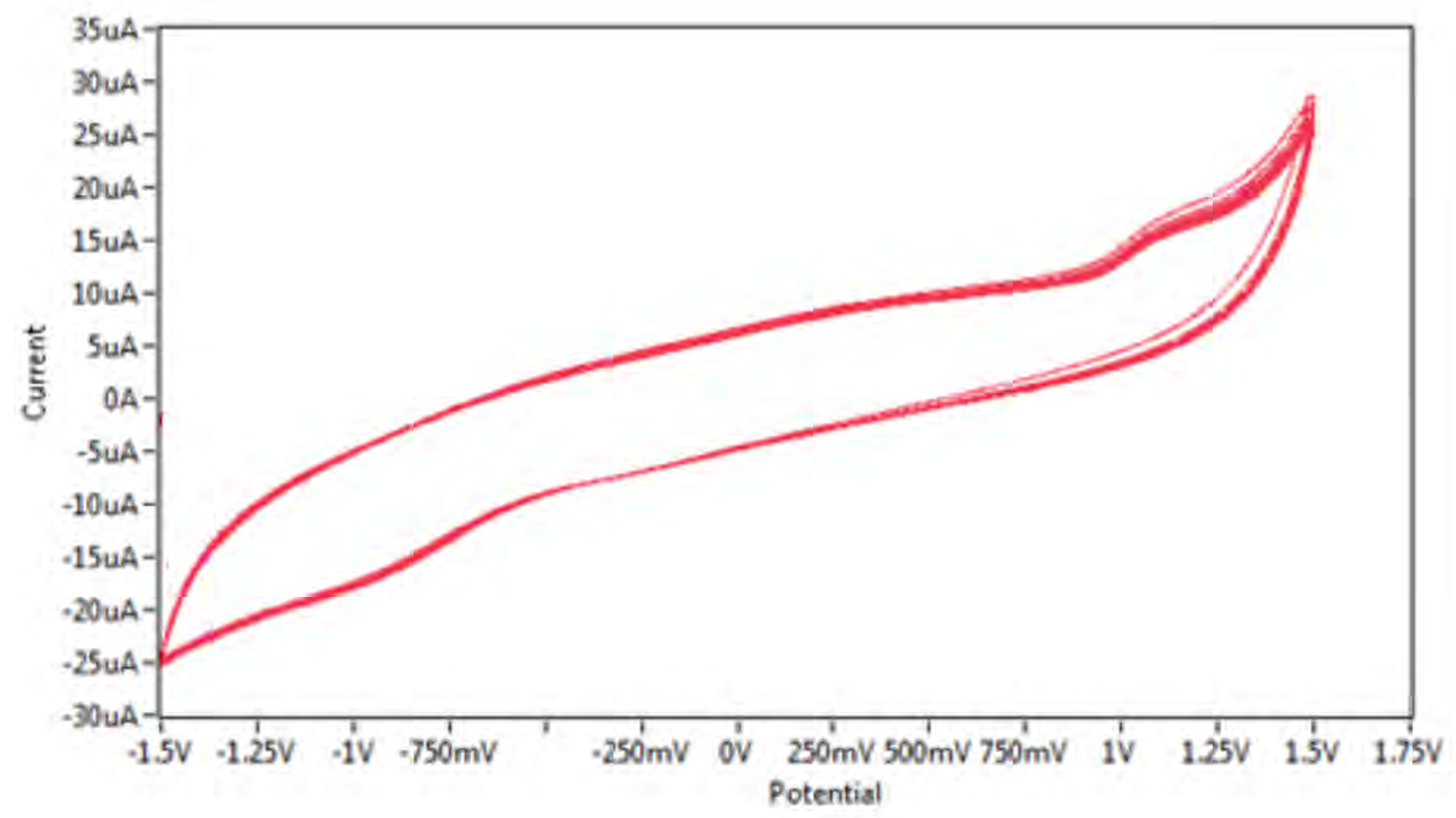

FIGURE 13. Cyclic voltammogram of Xylazine $2 \%$ and ketamine $10 \%$ in blood medium at ten times using $\mathrm{GCE}$ versus $\mathrm{Ag} / \mathrm{AgCl}$ reference electrode at scan rate $0.1 \mathrm{Vsec}-1$

When applying Randies equation to calculate the diffusion coefficient of oxidation - reduction reaction of the mix of $\mathrm{XZ}$ and $\mathrm{KN}$ in blood medi$\mathrm{um}$, it was found a good values of oxidation $\mathrm{D}_{\mathrm{f}, \mathrm{a}}$ is $5.12 \times 10^{-6}$ and of reduction $\mathrm{D}_{\mathrm{fc}}$ is $3.5 \times 10^{-6}$.

\section{Effect different pH (acidic and alkaline)}

In this study, each of $\mathrm{XZ}$ and $\mathrm{KN}$ have different electrochemical properties in different $\mathrm{pH}$ medium (acidic and alkaline), also, when used mix of XZ and $\mathrm{KN}$ in blood medium have different properties. Figure 12 shows that the oxidation peak of the mix of $\mathrm{XZ}$ and $\mathrm{KN}$ was disappeared in alkaline $\mathrm{pH}$, while the reduction peak enhanced in this $\mathrm{pH}$, so, the anesthesia (mix XZ and $\mathrm{KN}$ ) acts as anti-oxidative reagent in alkaline blood medium [21].

\section{Study reliability and stability}

To obtain the best results in this study, the glassy carbon electrode was used for effect mix of $\mathrm{XZ}$ and

\section{REFERENCES}

1. Muhammed Mizher Radhi, Hanaa Naji Abdullah, Majid Sakhi Jabir, Emad Abbas Jaffar Al-Mulla. Electrochemical Effect of Ascorbic Acid on Redox Current Peaks of $\mathrm{CoCl}_{2}$ in Blood Medium. Nano Biomed Eng. 2017;9(2):103-106.

2. Radhi MM, Abdullah $\mathrm{HN}, \mathrm{Al}-$ Asadi $\mathrm{SA}$ et al. Electrochemical oxidation effect of ascorbic acid on mercury ions in blood sample using cyclic voltammetry. Int J Ind Chem. 2015;6:311-316.
$\mathrm{KN}$ in the blood medium which has overlapping cyclic voltammogram for ten times as shown in Figure 13.

\section{CONCLUSIONS}

In practical veterinary anesthesia, the better method is using a mix of xylazine (XZ) and ketamine $(\mathrm{KN})$, which can ensure the safety in the blood of the animals. So, the using of electrochemical analysis by cyclic voltammetry a good method for oxidation-reduction peaks of the mix in the blood medium. The mix of anesthesia was found anti-oxidative of the blood medium comparing with using it as a single from the mix. Also, the mix of anesthesia of $\mathrm{XZ}$ and $\mathrm{KN}$ in the blood medium acts as an anti-oxidative reagent in alkaline $\mathrm{pH}$, while the mix of anesthesia ( $\mathrm{XZ}$ and $\mathrm{KN}$ ) act as oxidative stress for the blood components in acidic $\mathrm{pH}$.

Conflict of interest: none declared Financial support: none declared

3. Yousif Kadhim Abdul-Amir, Muhammed Mizher Radhi, Emad Abbas Jaffar Al-Mulla. Use of Nano-Sensors of the Interferences between $\mathrm{Pb}$ ((II) with Each of $\mathrm{Mg}(\mathrm{II}), \mathrm{Zn}(\mathrm{II}), \mathrm{Mn}(\mathrm{II}), \mathrm{Ca}(\mathrm{II}), \mathrm{Co}(\mathrm{II})$ and PO4-3 in Blood Medium: An Electrochemical Study. Nano Biomed Eng. 2017;9(3):199-207.

4. Alva N, Palomeque J, Carbonell T. Nitric oxide induced by ketamine/ xylazine anesthesia maintains hepatic blood flow during hypothermia. Nitric Oxide. 2006;15(1):64-69. 
5. Elvan Anadol, Gül Fatma Yarim, Nilgün Gültiken, Filiz Kazak. Effect of Ovariohysterectomy on Some Oxidative Stress Markers in the Rat. Harran Üniv Vet Fak Derg. 2016;5(2):124-128.

6. Ruiz-Colón K, Chavez-Arias C, Díaz-Alcalá JE, Martínez MA. Xylazine intoxication in humans and its importance as an emerging adulterant in abused drugs: A comprehensive review of the literature. Forensic Sci Int. 2014;240:1-8.

7. Green SM, Roback MG, Kennedy RM, Krauss B. Clinical Practice Guideline for Emergency Department Ketamine Dissociative Sedation: 2011 Update. Annals of Emergency Medicine. 2011;57(5):449-461.

8. Krishnaiah V, Reddy RCK, Reddy KM, Reddy YVM. Electrochemical Behavior and Analysis of Ketamine in Pharmaceutical Formulations by Voltammetric Techniques. Int J Pharm Sci Res. 2015; 6(5):2121-26.

9. Jing Zhou, Ying Xu, Le Wang, Jie Liu, Yamin Li, Baoxian Ye. Electrochemical Behavior and Voltammetric Determination of Ketamine at Pulse Plating Gold Film Modified Platinum Electrode. Journal of the Chinese Chemical Society 2012;59(7):879-883.

10. Lledo-Fernandez C, Pat Pollarda P, and Senee Kruanetr, Electroanalytical Sensing of Ketamine Using Electrogenerated Chemiluminescence, J. Electrochem. Soc. 2014;161(1):H36-H40.

11. Fu K, Zhang R, He J, Bai H, Zhang G. Sensitive detection of ketamine with an electrochemical sensor based on UV-induced polymerized molecularly imprinted membranes at graphene and MOFs modified electrode. Biosens Bioelectron. 2019;143:111636.

12. Mendes LF, Rodrigues Souza A, Bacil Prata R, De Araujo WA: Forensic electrochemistry: Electrochemical study and quantification of xylazine in pharmaceutical and urine samples. Electrochimica Acta. 2019;295:726-734.
13. El-Shal MA, Hendawy HAM. Highly Sensitive Voltammetric Sensor Using Carbon Nanotube and lonic Liquid Composite Electrode for Xylazine Hydrochloride, Anal Sci. 2019;35(2):189-194.

14. Instruction manual, CV 50W, version 11, Bioanalytical System Inc USA, (2013).

15. Cohen SP, Bhatia A, Buvanendran A, Schwenk ES, Wasan AD, Hurley RW et al. Consensus Guidelines on the Use of Intravenous Ketamine Infusions for Chronic Pain From the American Society of Regional Anesthesia and Pain Medicine, the American Academy of Pain Medicine, and the American Society of Anesthesiologists. Reg Anesth Pain Med. 2018; 43(5):521-546.

16. Kopsky DJ, Keppel Hesselink JM, Bhaskar A, Hariton G, Romanenko $\mathrm{V}$, Casale R. Analgesic effects of topical ketamine. Minerva Anestesiol. 2015; 81(4):440-9.

17. Albrecht M, Henke J, Tacke S. Effects of isoflurane, ketamine-xylazine and a combination of medetomidine, midazolam and fentanyl on physiological variables continuously measured by telemetry in Wistar rats. BMC Vet Res. 2014;10:198-212.

18. Rahimnejada M, Zokhtareha R, Akbar A. Moghadamnia and Maryam Asghary, An Electrochemical Sensor Based on Reduced Graphene Oxide Modified Carbon Paste Electrode for Curcumin Determination in Human Blood Serum. Portugaliae Electrochimica Acta 2020;38(1):29-42.

19. Zanello P, Nervi C, de Biani FF. Inorganic electrochemistry: Theory, practice and application. The Royal Society of Chemistry 2003; 212-220.

20. Skoog DA, Holler FJ, Crouch SR. Principles of instrumental analysis. Brooks Cole, 2006.

21. Cotton F, Geoffrey W. Advanced Inorganic Chemistry, Fifth edition, John Wiley and Sons, 1988). 